\title{
Quantum confinement effects of Si/SiGe strained-layer superlattices grown by an ultrahigh vacuum/chemical vapor deposition technique
}

\author{
T. C. CHANG \\ National Nano Device Laboratory, Hsinchu, Taiwan \\ C. Y. CHANG, T. G. JUNG, P. A. CHEN, W. C. TSAI \\ Institute of Electronics, National Chiao Tung University, Hsinchu, Taiwan \\ P. J. WANG \\ National Nano Device Laboratory, Hsinchu, Taiwan \\ Y. F. CHEN, S. C. PAN \\ Department of Physics, National Taiwan University, Taipei, Taiwan
}

Well-resolved band-edge luminescence is observed for $\mathrm{Si}_{0.86} \mathrm{Ge}_{0.14} / \mathrm{Si}$ strained-layer superlattices grown by an ultrahigh vacuum/chemical vapour deposition technique at $550^{\circ} \mathrm{C}$. High-resolution double-crystal $X$-ray diffraction (HRXRD) and cross-sectional transmission electron microscopy (XTEM) were used to determine the strain and other parameters for these strained-layer superlattices. Quantum confinement is observed for a SiGe well as thin as $1.3 \mathrm{~nm}$. The blue shift of the emission peaks with decreasing well width is found to be in good agreement with theoretical calculation.

\section{Introduction}

$\mathrm{Si}_{1-x} \mathrm{Ge}_{x} / \mathrm{Si}$ strained-layer superlattices (SLS) have received increasing attention recently because of their potential application in silicon-base high-speed electronic circuits as well as in new optoelectronic devices [1-4]. In the field of optoelectronics, due to their inherent indirect band structure and the creation of defects caused by the lattice mismatch, it is quite a challenge for researchers to consider silicon-based alloys as a promising candidate for light-emitting materials. With the improvement in the quality of the grown material, it has been possible to observe the well-resolved band-edge luminescence and the shift of emissions with varying well width in $\mathrm{Si}_{1-x} \mathrm{Ge}_{x} / \mathrm{Si}$ strained-layer quantum wells $[5,6]$. For minimizing problems associated with lattice mismatch and interdiffusion, a low temperature process is desirable to obtain high-quality $\mathrm{Si}_{1-x} \mathrm{Ge}_{x} / \mathrm{Si}$ SLSs.

Molecular beam epitaxy (MBE) is known as one of the most popular low-temperature epitaxial growth techniques for $\mathrm{Si} / \mathrm{SiGe}$ heteroepitaxy [7]. However, due to its use of solid sources, this technique suffers difficulties in avoiding microclustering and compositional grading. Thickness variations and interdiffusion were also observed for $\mathrm{Si} / \mathrm{SiGe} \mathrm{SLSs}$ grown by MBE [8]. In addition to $\mathrm{MBE}$, other techniques, such as limited reaction process-chemical vapour deposition (LRP-CVD) [9], and plasma enhanced CVD techniques [10], were also demonstrated to have the capability of growing high-quality $\mathrm{Si} / \mathrm{SiGe}$ hetero- structures at low temperatures. However, these techniques have not succeeded in growing thin $\mathrm{Si} / \mathrm{SiGe}$ heterostructures with interface qualities as abrupt as those grown by MBE. On the other hand, recent developments of the ultrahigh vacuum/chemical vapour deposition (UHV/CVD) technique have significantly advanced the field of $\mathrm{Si} / \mathrm{SiGe}$ heteroepitaxy [11, 12]. This technique has the advantages of a CVD process, such as simplicity, high purity, high throughput, etc., and also holds very tight controls on layer thickness, chemical composition and interfacial abruptness at low growth temperatures. To date, many outstanding high-performance and high-speed $\mathrm{Si}$ SiGe devices have been demonstrated by incorporating this growth technique [13]. In terms of $\mathrm{Si} / \mathrm{SiGe}$ SLS, Wang et al. [14] have demonstrated excellent growth with the UHV/CVD system and subsequently Zollner et al. [15] observed photoluminescence (PL) from these SLSs. However, a large discrepancy was present between the PL experimental value and theoretical calculation for their SLS with the narrowest well width of $3 \mathrm{~nm}$. Film quality and PL of Si/SiGe SLSs with well widths thinner than $3 \mathrm{~nm}$ have not been explored.

In this work, we report clear band-edge luminescence of $\mathrm{Si}_{0.86} \mathrm{Ge}_{0.14} / \mathrm{Si}$ SLSs with SiGe well width as thin as $1.3 \mathrm{~nm}$ grown by a home-made UHV/CVD system. The blue shift of the emission peak with decreasing well width is found to be in good agreement with theoretical calculation. Since structural 
parameters and film quality strongly influence the PL from $\mathrm{Si}_{1-x} \mathrm{Ge}_{x} / \mathrm{Si}$ SLSs, high-resolution doublecrystal X-ray diffraction (HRXRD) and cross-sectional transmission electron microscopy (XTEM) were used to determine the strain, layer thickness and $\mathrm{Ge}$ compositional uniformity. A dynamical X-ray simulation program based on the solution of TakagiTaupin equations was employed to analyse the experimental rocking curves obtained from these SLSs [16]. Detailed comparisons between the experimental rocking curves and the theoretical ones were made to extract the crystalline quality, layer thickness and compositional uniformity of these SLSs.

\section{Experimental procedure}

$\mathrm{Si} / \mathrm{SiGe} \mathrm{SLSs}$ were grown on 3 inch (001) Si substrates using a home-made hot-wall multiwafer UHV/CVD system. The UHV/CVD technique was first described and developed by Meyerson. The construction and operation of our UHV/CVD system is similar to that reported [11]. The system was designed and built at National Chiao Tung University and has been successfully used to grow epitaxial layers of both $\mathrm{Si}$ and $\mathrm{Si}_{1-x} \mathrm{Ge}_{x}$ at temperatures as low as $550^{\circ} \mathrm{C}$. Details of our UHV/CVD system will be published elsewhere [17]. In this work, the growth temperature was kept constant at $550^{\circ} \mathrm{C}$. Prior to growth, the substrate was subjected to a $\mathrm{H}_{2} \mathrm{SO}_{4}: \mathrm{H}_{2} \mathrm{O}_{2}=3: 1$ clean and a $10 \% \mathrm{HF}$ dip. Silane $\left(\mathrm{SiH}_{4}\right)$ and $10 \%$ germane $\left(\mathrm{GeH}_{4}\right)$ in hydrogen were used as reactant gases. The base pressure of the system was maintained at about $2.7 \times 10^{-6} \mathrm{~Pa}$ in the growth chamber. During growth, the system was operated at about $0.13 \mathrm{~Pa}$. Growth was initiated by depositing a thin $\mathrm{Si}$ film of $10 \mathrm{~nm}$ thickness. During subsequent growth, the $\mathrm{SiH}_{4}$ flow rate was kept constant at $20 \mathrm{sccm}$ and the $\mathrm{GeH}_{4}$ flow rate at $6 \mathrm{sccm}$. A ten-second growth interruption was employed after each $\mathrm{Si}_{1-x} \mathrm{Ge}_{x}$ layer growth while no interruption was used after each Si layer growth. The reason for employing the growth interruption is that the growth rate of $\mathrm{Si}_{1-x} \mathrm{Ge}_{x}$ is much higher than that of the Si layer. For a Ge atomic mole fraction $x$ of $\mathrm{Si}_{1-x} \mathrm{Ge}_{x}$ in $\mathrm{Si} / \mathrm{SiGe}$ SLS of about 0.14 , the growth rates of $\mathrm{Si}$ layers and $\mathrm{Si}_{1-x} \mathrm{Ge}_{x}$ layers were about $0.8 \mathrm{~nm} \mathrm{~min}^{-1}$ and $5 \mathrm{~nm} \mathrm{~min}{ }^{-1}$, respectively.

HRXRD was used to determine the structural qualities of these superlattices. X-ray rocking curves were obtained by using a Phillips DCD-3 double-crystal diffractometer. The system was operated in the parallel $(+,-)$ diffraction geometry using $\mathrm{CuK}_{\alpha}$ radiation. A Si single crystal with (004) symmetric reflection was used as the first reflection. A dynamical $\mathrm{X}$-ray simulation program was also used to determine

TABLE I Structural parameters for $\mathrm{Si}_{1-x} \mathrm{Ge}_{x} / \mathrm{Si}$ SLSs.

\begin{tabular}{lccll}
\hline Sample & $t_{\text {SiGe }}(\mathrm{nm})$ & $t_{\mathrm{Si}}(\mathrm{nm})$ & $x$ & $N$ \\
\hline 1 & 19.3 & 22.0 & 0.14 & 10 \\
2 & 8.7 & 11.0 & 0.14 & 20 \\
3 & 4.0 & 6.8 & 0.14 & 40 \\
4 & 1.3 & 3.8 & 0.14 & 80 \\
\hline
\end{tabular}

$t_{\mathrm{SiGe}}:$ Thickness of SiGe layer; $t_{\mathrm{Si}}:$ thickness of Si layer; $x$ : Ge molar fraction; $N$ : number of periods. layer thickness and Ge composition of these SLSs. Cross-sectional transmission electron microscopy was performed to examine the crystal quality and layer thickness. For the photoluminescence measurement, the sample was placed in a Janis cryostat with the temperature varying from 10 to $300 \mathrm{~K}$. An Argon ion laser with $2.54 \mathrm{eV}$ was used as the pumping source. The luminescence signal was analysed by a $0.75-\mathrm{m}$ double spectrometer and detected by a liquid-nitrogen-cooled Ge detector (North Coast 817L) connected to a lock-in amplifier.

\section{Results and discussion}

Four $\mathrm{Si}_{1-x} \mathrm{Ge}_{x} / \mathrm{Si} \mathrm{SLSs}$ of various periodicities and layer thicknesses were grown using an UHV/CVD system. Structural parameters for these SLSs are listed in Table I. The widths of SiGe wells for these SLSs are $19.3 \mathrm{~nm}, 8.7 \mathrm{~nm}, 4 \mathrm{~nm}$ and $1.3 \mathrm{~nm}$ for Sample 1, Sample 2, Sample 3 and Sample 4, respectively. Fig. $1 \mathrm{a}-\mathrm{d}$ shows the HRXRD rocking curves obtained for these samples. In this figure, peak sub represents the $\mathrm{Si}$ substrate reflection, peak $\mathrm{P} 0$ the zeroth-order superlattice reflection, and other main peaks are satellite peaks $(+3,+2,+1,-1,-2,-3)$ resulting from the periodicity of the superlattice. Besides those main peaks, a number of secondary peaks are observed, which are interference reflections corresponding to the number of periods in the superlattice. The Ge fraction $x$ and the thickness of the $\mathrm{Si}\left(t_{\mathrm{Si}}\right)$ and $\mathrm{Si}_{1-x} \mathrm{Ge}_{x}\left(t_{\mathrm{SiGe}}\right)$ layers in a superlattice were determined from a comparison of simulated and experimental double-crystal rocking curves.

Fig. 2a shows the HRXRD rocking curve obtained for Sample 2 and Fig. $2 b$ shows the simulated rocking curve for a fully-strained $\mathrm{Si}_{1-x} \mathrm{Ge}_{x} / \mathrm{Si}$ superlattice of 20

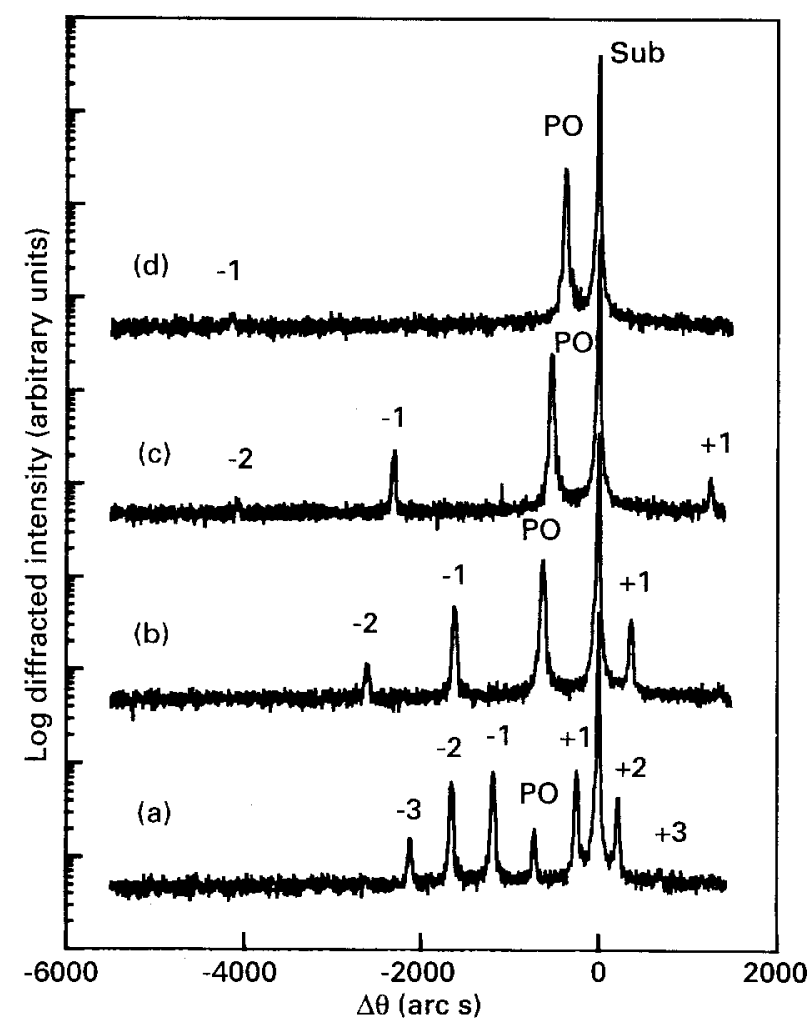

Figure 1 HRXRD rocking curves for SLSs grown for this work. (a) Sample 1; (b) Sample 2; (c) Sample 3; (d) Sample 4. 


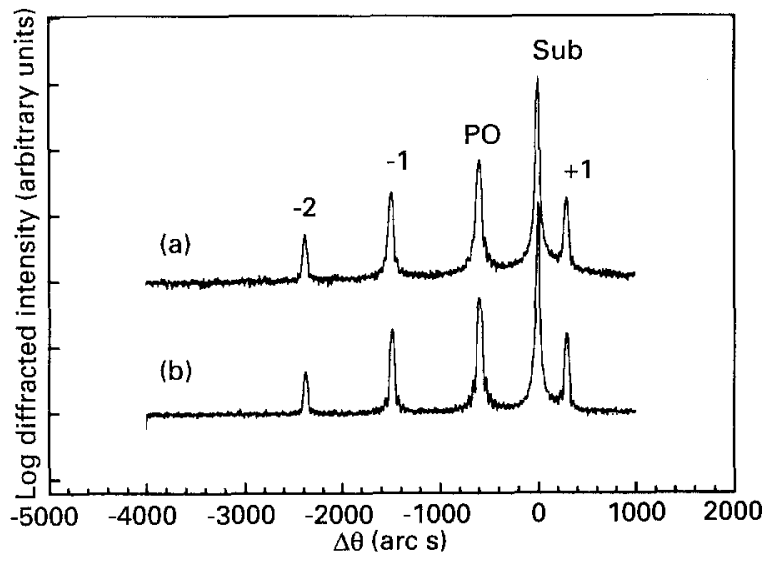

Figure 2 (a) HRXRD rocking curve for sample 2; (b) simulated rocking curve for a $\mathrm{Si} / \mathrm{SiGe}$ SLS of 20 periods with $\mathrm{Si} 11 \mathrm{~nm}, \mathrm{SiGe}$ $8.7 \mathrm{~nm}$ and $14 \% \mathrm{Ge}$.

periods with $x=0.14$, Si $11 \mathrm{~nm}, \mathrm{SiGe} 8.7 \mathrm{~nm}$. In this simulated rocking curve, we have considered the effect of diffused scattering from the first crystal and substrate [14]. When compared to Fig. 2a, excellent matches between experiment and simulation in terms of peak position, peak intensity, and full width at half maximum (FWHM) of each main peak are clearly observed. Since the simulated rocking curve is based on an assumption that all layers in the superlattice are perfect with regard to the crystal quality, layer thickness and alloy composition uniformity, it can be concluded that the Sample 2 has no detectable layer variation. This point has been further confirmed by the conventional and high-resolution cross-sectional transmission electron microscopic examination for this sample [18].

Fig. 3a shows the HRXRD rocking curve obtained for Sample 4. Each layer thickness of this sample is the thinnest of all the four superlattices grown for this work. Similarly, Fig. 3b shows the best-fit simulated rocking curve based on a full-strained $\mathrm{Si}_{1-x} \mathrm{Ge}_{x} / \mathrm{Si}$ superlattice of 80 periods with $x=0.14$, Si $3.8 \mathrm{~nm}$ and SiGe $1.3 \mathrm{~nm}$. On comparison, excellent matches between experiment and theory in terms of peak position, peak intensity, and full width at half maximum (FWHM) of each main peak are again obtained. Fig. 4 shows the XTEM micrograph of Sample 4. In this picture, each layer of the superlattice is clearly resolved. Good periodic structure with excellent layer thickness uniformity were observed. The thicknesses of $\mathrm{Si}$ and $\mathrm{SiGe}$ layers were measured to be 3.7 $\pm 0.5 \mathrm{~nm}$ and $1.3 \pm 0.5 \mathrm{~nm}$, respectively. These values agree well with the $\mathrm{X}$-ray simulation results. Overall, the degree of tight control made possible by the UHV/CVD system of SLS with ultrathin layer thickness was demonstrated by the XTEM micrograph and HRXRD of Sample 4.

Fig. 5 shows a typical band-edge PL spectrum taken at $10 \mathrm{~K}$ for a $\mathrm{Si}_{0.86} \mathrm{Ge}_{0.14} / \mathrm{Si} \mathrm{SLS}$ with $\mathrm{SiGe}$ well width of $4.0 \mathrm{~nm}$. To identify the origin of the emission peaks, we follow the assignment made by Weber and Alosno [19]. The emission at $1098 \mathrm{meV}$ is due to excitonic radiative recombination of excitons, created in the Si substrate, with the assistance of transverse

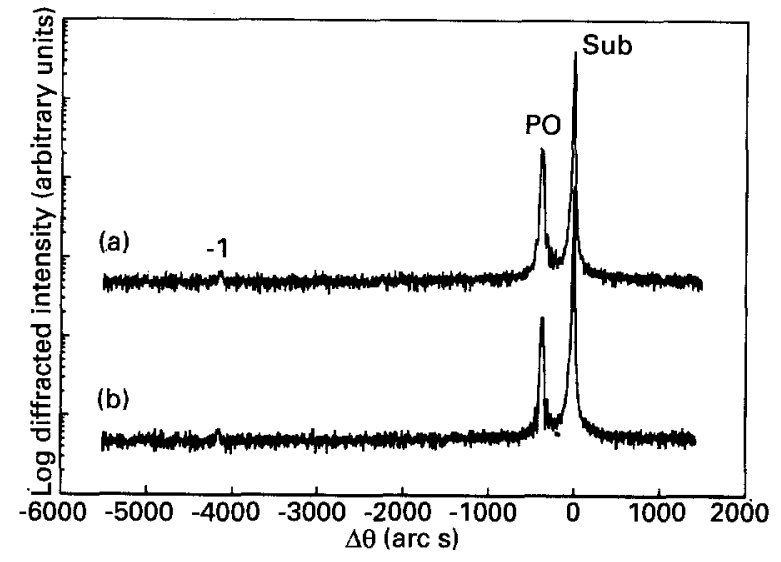

Figure 3 (a) HRXRD rocking curve for sample 4; (b) simulated rocking curve for a Si/SiGe SLS of 80 periods with $\mathrm{Si} 3.8 \mathrm{~nm}$, SiGe $1.3 \mathrm{~nm}$ and $14 \% \mathrm{Ge}$

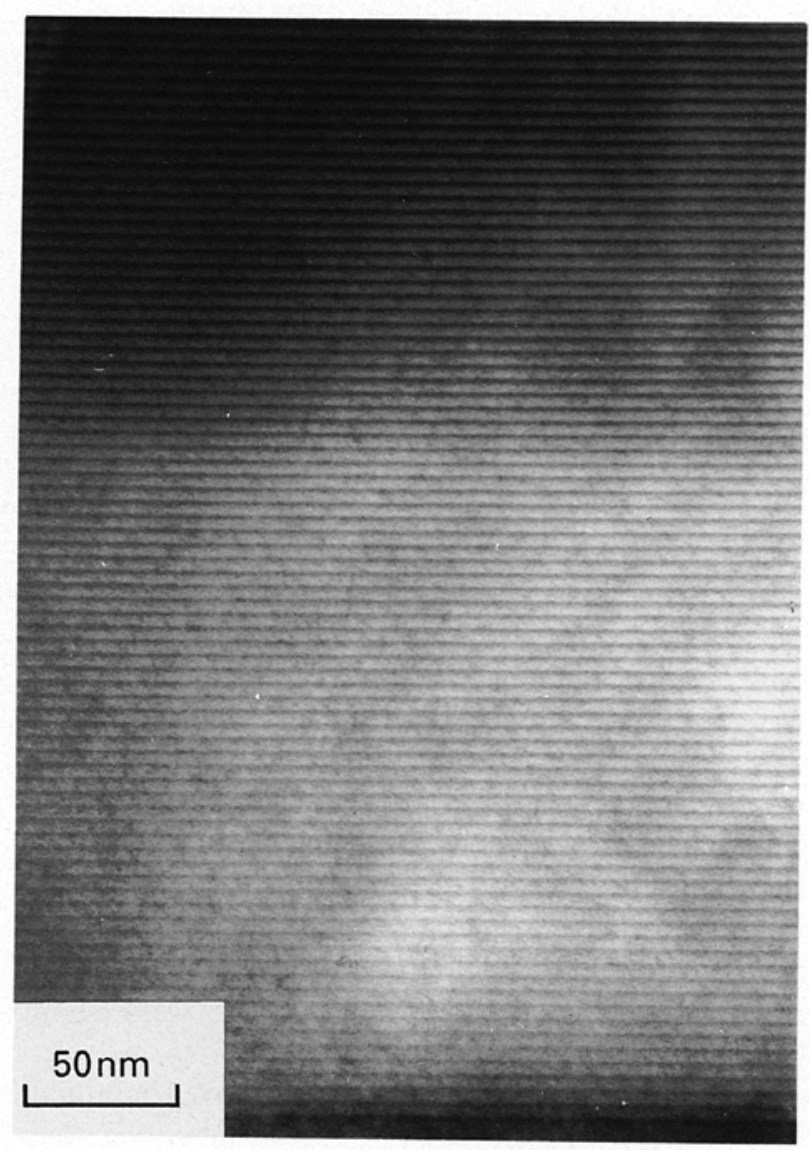

Figure 4. A typical XTEM micrograph for Sample 4. Bright and dark regions represent $\mathrm{Si}$ and $\mathrm{SiGe}$ layers, respectively.

optical (TO) photons (58 meV). Intense luminescence lines, labelled as NP and $\mathrm{TO}^{\mathrm{Si}-\mathrm{Si}}$, are no-phonon and transverse optical-phonon-assisted emission, originating from SiGe wells of SLS, respectively. The energy difference of $58 \mathrm{meV}$ between NP and $\mathrm{TO}^{\mathrm{Si}-\mathrm{Si}}$ lines closely matches the TO phonon energy of Si. Phononassisted emission due to $\mathrm{Si}-\mathrm{Ge}$ and $\mathrm{Ge}-\mathrm{Ge}$ TO phonons and transverse acoustic (TA) phonons are also observed between NP and $\mathrm{TO}^{\mathrm{Si}-\mathrm{Si}}$ emission lines. Strong NP emission is a magnification of the broken translation symmetry of SiGe layers and is effected through momentum-conserving scattering due to 


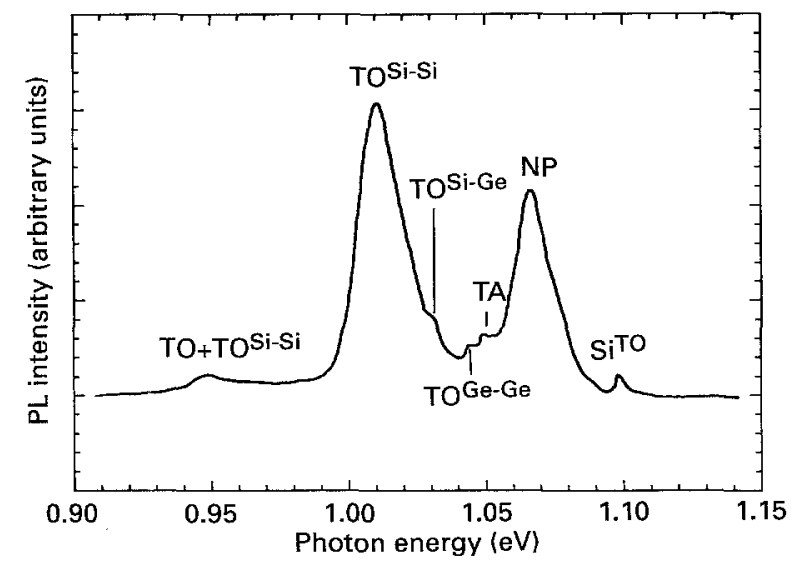

Figure 5 A typical band-edge PL spectrum taken at $10 \mathrm{~K}$ of a $\mathrm{Si}_{0.86} \mathrm{Ge}_{0.14} / \mathrm{Si}$ SLS with $\mathrm{SiGe}$ well width of $4.0 \mathrm{~nm}$.

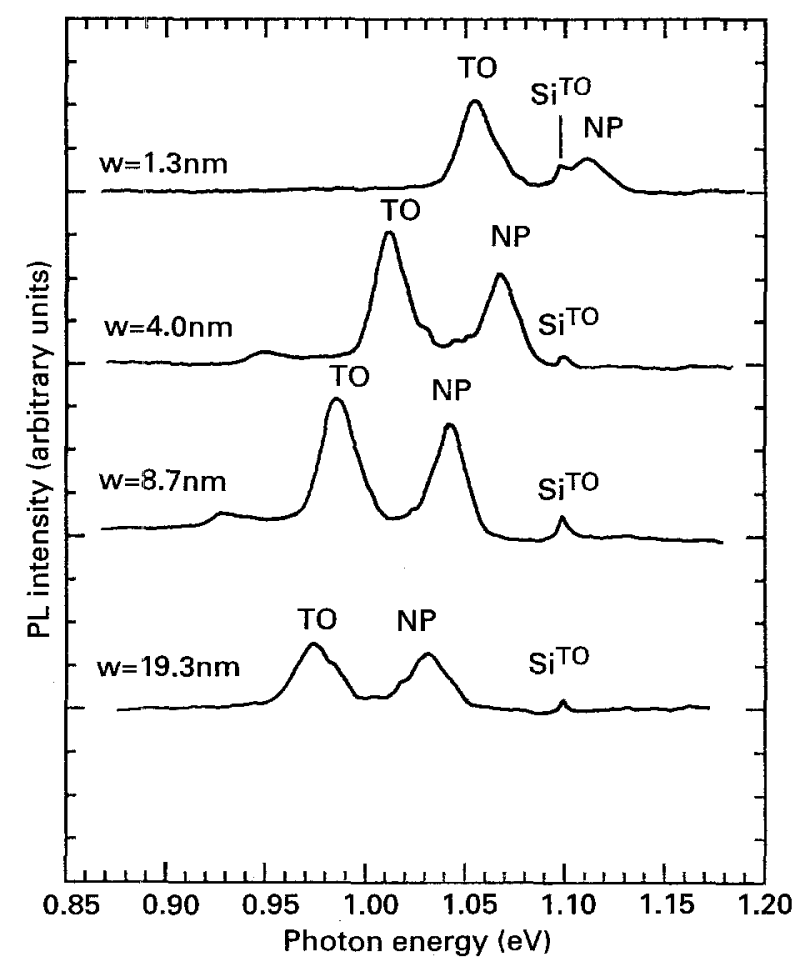

Figure 6 Photoluminescence spectra at $10 \mathrm{~K}$ for $\mathrm{Si}_{0.86} \mathrm{Ge}_{0.14} / \mathrm{Si}$ SLSs with SiGe well width of $1.3,4.0,8.7$, and $19.3 \mathrm{~nm}$, respectively.

compositional disorder in SiGe. The lowest energy component $\left(\mathrm{TO}+\mathrm{TO}^{\mathrm{Si}-\mathrm{Si}}\right)$ in Fig. 5, which has not been identified before, can be attributed to twophonon replica, since the energy difference between this peak and the NP line is equal to twice the TO phonon energy of Si.

Fig. 6 shows PL spectra at $10 \mathrm{~K}$ for these four $\mathrm{Si}_{0.86} \mathrm{Ge}_{0.14} / \mathrm{Si}$ SLSs with $\mathrm{SiGe}$ well width ranging from 1.3 to $19.3 \mathrm{~nm}$. The emission $\mathrm{Si}^{\mathrm{TO}}$ at $1098 \mathrm{meV}$, which does not change with varying quantum well width, is due to the exciton assisted by transverse optical phonons in the Si crystal. The peak positions of NP and TO are obviously shifted to higher energies with decreasing SiGe well width, which is an indication of the effect of quantum confinement. Particularly, the energy of NP is higher than that of $\mathrm{Si}^{\mathrm{TO}}$ for the SLS with the narrowest SiGe well width of $1.3 \mathrm{~nm}$. To our knowledge, we are the first to observe this phenomenon. This finding can be attributed to both small SiGe well width and excellent interfaces of $\mathrm{Si} / \mathrm{SiGe} \mathrm{SLS}$. In this figure the relative intensity of NP and TO emission, $I_{\mathrm{NP}} / I_{\mathrm{TO}}$, was also found to decrease with decreasing well width. The result can be attributed to the penetration of excitonic wave functions into the Si barriers upon reduction of the well width. As the excitons wave function penetrates into the $\mathrm{Si}$ barriers, the relative exciton wave function remaining in the SiGe well becomes weaker, which reduces the probability of NP emission.

For a more quantitative comparison with the theory, we calculate the energy gap by a standard square potential model. From the results of HRXRD, all $\mathrm{SiGe}$ layers of the four samples are full-strained. Since the $\mathrm{SiGe}$ is biaxially strained and under compressive conditions, 6-fold degenerate conduction band minima split into low-lying in-plane 4-fold states and 2-fold degenerate states in the growth direction [20]. Similarly, the valance band splits into heavyhole and light-hole states. According to the theoretical calculation of Van de walle and Martin [21], the band alignment for the $\mathrm{Si}_{0.86} \mathrm{Ge}_{0.14} / \mathrm{Si}$ heterostructure should be of type-I with conduction and valence band offsets being 9 and $120 \mathrm{meV}$, respectively. Since the effective mass is position-dependent in the $\mathrm{SiGe} / \mathrm{Si}$ heterostructure system, the appropriate effective Hamiltonian operator should include the discontinuities of the effective masses at the heterointerfaces. In this calculation, the Hamiltonian proposed by BenDaniel and Duke is used [22]. Numerical techniques (often referred to as the inverse power method) [23] are applied to solve the Schröding equation. Electron and heavy-hole effective masses of the full-strained SiGe layer are assumed to be $0.19 \mathrm{~m}_{0}$ and $0.28 \mathrm{~m}_{0}$, respectively, where $m_{0}$ is the mass of the free electron $[24,25]$. The conduction band offset is too small, therefore, we have focused on the valence band and neglected the confinement effect in the conduction band in our calculation. Moreover, the coupling effect of superlattices has been neglected due to the fairly large valance band masses (compared to electrons in an $\mathrm{Al}_{1-x} \mathrm{Ga}_{x} / \mathrm{GaAs}$ superlattice). The calculated results are represented by the solid curves, as shown in Fig. 7. Phonon-assisted emission energy (lower TO solid curve) was drawn by displacing the NP emission exactly $58 \mathrm{meV}$ lower in energy regardless of the well width. In these calculated curves, the exciton binding energy $(15 \mathrm{meV})$ has been taken into account [6]. The square and circle points in Fig. 7 are the energy positions of NP and TO peaks obtained from Fig. 6. It is evident that the calculated and experimental values are in close agreement. Thus, the results shown here not only provide evidence demonstrating the quantum confinement shift in high-quality $\mathrm{SiGe} / \mathrm{Si}$ SLSs grown by the UHV/CVD technique at low temperatures but also unambiguously shows the band-edge luminescence. Recently, we observed room-temperature quantum confinement for those thin-layer SLSs using a photothermal deflection spectroscopy (PDS) technique [26], which provides further evidence for high crystalline quality and excellent interfaces of $\mathrm{Si} / \mathrm{SiGe}$ superlattices grown by the UHV/CVD system. 


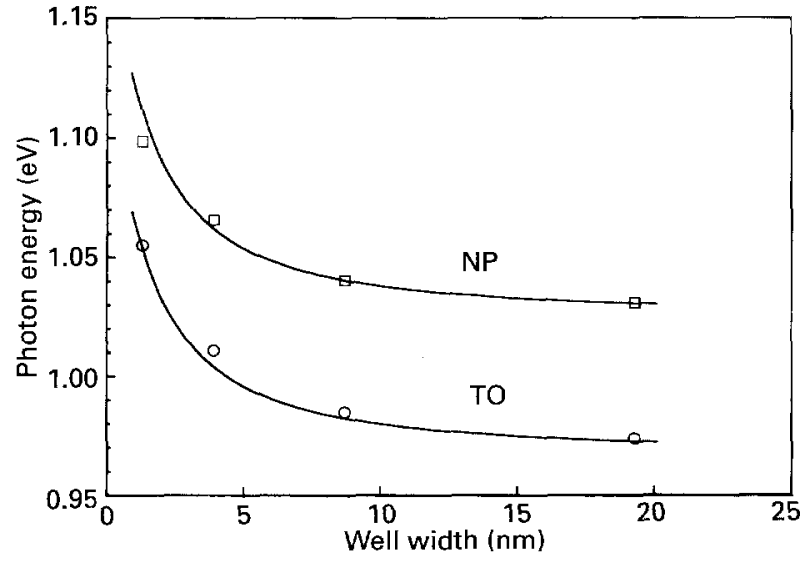

Figure 7 Emission energy as a function of SiGe well width, showing the blue shift of NP and TO emission energies. Solid lines are the calculated results in which the exciton binding energy $(15 \mathrm{meV})$ has been used in the calculation.

\section{Conclusion}

We have observed well-defined band-edge excitonic luminescence for $\mathrm{Si}_{0.86} \mathrm{Ge}_{0.14} / \mathrm{Si}$ SLSs grown by the UHV/CVD technique at low temperature $\left(550^{\circ} \mathrm{C}\right)$. HRXRD, X-ray simulation and XTEM were applied to evaluate the crystalline quality and strain of these superlattices. Full-strained high-quality $\mathrm{SiGe} / \mathrm{Si}$ superlattices with $\mathrm{SiGe}$ well width as thin as $1.3 \mathrm{~nm}$ were achieved. Quantum confinement was also observed for these SLSs. Excellent matches between experimental and theoretical PL emission line energies demonstrate the capability of the UHV/CVD system for preparing excellent nanometre-thick $\mathrm{Si}$ / SiGe heterostructures.

\section{Acknowledgements}

This work is in part supported by the National Science Council under contract No. NSC-82-0404E009-233, Republic of China.

\section{References}

1. K. TERASHIMA, M. TAJIMAN and T. TATSUMi, Appl. Phys. Lett. 57 (1990) 1952.

2. N. L. ROWELL, J.-P. NOËL, D. C. HOUGHTON and M. BUCHANAN, Appl. Phys. Lett. 58 (1991) 957.

3. V. ARBET-ENGELS, M. A. KALLEL and K. L. WANG, ibid. 59 (1991) 1705.
4. D. C. HOUGHTON, J.-P. NOËL and N. L. ROWELL, Mater. Res. Soc. Symp. Proc. 220 (1991) 299.

5 X. XIAO, C. W. LIU, J. C. STURM, L. C. LENCHYSHYN, M. L. THEWALT, R. B. GREGORY and P. FEJES, Appl. Phys. Lett. 60 (1992) 2153.

6. S. FUKATSU, H. YOSHIDA, N. USAMI, A. FUJIWARA, Y. TAKAHASHI, Y. SHIRAKI and R. ITO, Jpn. J. Appl. Phys. 31 (1992) L1319.

7. P. C. ZALM, G. F. A. VAN DE WALLE, D. J. GRAVESTEIJN and A. A. VAN GOR K UM, Appl. Phys. Lett. 55 (1989) 2520

8. S. J. BARNET and G. T. BROWN, ibid. 54 (1989) 1781.

9. C. M. GRONET, C. A. KING, W. OPYD, J. F. GIBBONS, S. D. WILSON and R. HULL, J. Appl. Phys. 61 (1987) 2407.

10. D. KINOSDY, R. QIAN, J. IRBY, T. HSU, B. ANTHONY, S. BANERJEE, A. TASCH, C. MAGEE and C. L. GROVE, Appl. Phys. Lett. 59 (1989) 817

11. B. S. MEYERSON, ibid. 48 (1986) 797.

12. B. S. MEYERSON, K. J. URAM and F. K. LEGOUES, ibid. 53 (1988) 2555.

13. G. L. PATTON, J. H. COMFORT, B. S. MEYERSON, E. F CRABBÉ, G. L. SCILLA, E. DEFRÉSAR'T, J. M. STORK, J. Y.-C. SUN, D. L. HARAME and J. N. BURGHARTZ, IEEE Electron. Device Lett. 11 (1990) 171.

14. P. J. WANG, M. S. GOORSKY, B. S. MEYERSON, F. K LEGOUES and M. J. TEJWANI, Appl. Phys. Lett. 59 (1991) 814.

15. S. ZOLLNER, R. T. COLLINS, M. S. GOORSKY, P. J. WANG, M. J. TEJWANI, J. O. CHU, B. S. MEYERSON and F. K. LEGOUES, Proc. SPIE 1678 (1992) 81

16. PC-HRS simulation software, Phillips.

17. T. G. JUNG, C. Y. CHANG, T. C. CHANG and P. J. WANG, Jpn. J. Appl. Phys. Part. 133 (1994) 224.

18. T. C. CHANG, C. Y. CHANG, T. G. JUNG, W. C. TSAI and P. J. WANG, J. Appl. Phys. 75 (1994)

19. J. WEBER and M. I. ALOSNO, Phys. Rev. B40 (1989) 5683.

20. U. GNUTZMANN and K. ClAUSECKER, Appl. Phys. 3 (1974) 9.

21. C. G. VAN DE WALLE and R. M. MARTIN, Phys. Rev. B34 (1986) 5621.

22. D. J. BENDANIEL and C. B. DUK E, Rev. B24 (1966) 683.

23. G. W. STEWAR D, in "Introduction to matrix computations" (Academic, New York, 1973) Ch. 7.

24. J. I. PANKOVE, in "Optical Processes in Semiconductors" (Dover, New York, 1971)

25. R. P. G. KARUNASIRI, J. S. PARK, Y. J. MII and K. L. WANG, Appl. Phys. Lett. 57 (1990) 2585.

26. Y. F. CHEN, Y. T. DAI, H. P. CHOU, T. C. CHANG, C. Y. CHANG and P. J. WANG, ibid. 62 (1993) 2713.

Received 8 December 1993

and accepted 7 March 1994 